\title{
Critical Thinking in Academic Writing Amongst Rukwangali Students: Lecturers' Perspectives
}

\author{
${ }^{a}$ Natalia S. Intja, Martha Nahole \\ anreino@unam.na \\ University of Namibia, Rundu Campus, Kaisosi Road, Windhoek 88, Namibia \\ University of Namibia, Rundu Campus, Kaisosi Road, Windhoek 88, Namibia
}

\begin{abstract}
This article is a part of a larger study that explored the perspectives of Rukwangali education lecturers towards Rukwangali students' critical thinking in academic writing. The main aim is not only to bring into focus the strategies towards lecturing for critical thinking in academic writing, but also to highlight some of the barriers to successful integration by Rukwangali language education students in academic writing and also to elicit perceptions that would impede Rukwangali language lecturers to lecture for critical thinking. On the basis of a critical review of literature, claims about the role of critical thinking in higher education are discussed and the synergies concerning critical thinking and academic are discussed. With the growing enthusiasm for critical thinking and academic writing in higher institutions of learning, a plethora of authors around critical thinking and academic writing have claimed that critical thinking and academic writing have a pivotal role in shaping students. Indeed, these concepts are useful for different solicitations. However, there are certain barriers that can prevent students from utilizing critical thinking in academic writing and lecturers from incorporating critical thinking in their content delivery and assessments even if the definitions and approaches exist. A qualitative design was used in the process of data collection and analysis. A purposive sample of four Rukwangali language education lecturers participated in the study. The findings of the study has led to the acknowledgement that the inability of critical thinking in academic writing by students is influenced by a combination of factors such as subject knowledge, authorial voice, the essay genre, parental education, lack of enough efforts from colleges and universities, teacher competence, nature of students, type of learning environment, organisational ethos and resources, content driven curricula, assessment criteria, inability to translate content and language barrier. Whereas, a lack of training, lack of information, personal beliefs and preconceptions and time constraints are singled out to be stumbling blocks for Rukwangali lecturers in implementing critical thinking strategies into their lectures. The article concludes by making recommendations that a closer look at these factors and their solutions would be beneficial in making the skill of critical thinking in academic writing more effective in mitigating the inability of students' critical thinking in Rukwangali academic writing at Unam's Rundu campus.
\end{abstract}

Keywords: Critical Thinking; Academic Writing; Rukwangali; Rundu Campus

\section{Background}

The importance of critical thinking in higher education is well documented. Moon (2008) alludes that critical thinking is considered to be central to higher levels of education or a fundamental goal of learning. It is also a process involved in any research activity. Beyond this however, and more significantly, critical thinking 
is an element in many level and qualification descriptors for education. Furthermore, Bahr (2010) concur with Moon (2008) and state that critical thinking has subsequently emerged as a key element in the published graduate capabilities. Moreover, it is important to engage in critical thinking for students own academic development and to demonstrate this capacity as a part of achieving the requisite graduate attribute and to understand its role in their future professional practice as scholars. Rezaei, Derakhshan \& Bagherkazemi (2011) assert that meaningful education halts students from involving in the unreflective learning of information, and equips them with the tools necessary to understand thoroughly the world they are in.

This problem (students' inability of critical thinking in academic writing: perspectives of Rukwangali language lecturers' at Rundu Campus) was identified by the researcher during the assessment of students' academic work and during lectures at the University of Namibia's (UNAM's) Rundu Campus as one of the grave concern leading to students' high failure rate. As observed, students do not pay more attention when they write and have a perception of producing pieces of writings in quantity rather than quality, they cannot make logical arguments or conclusions in their academic writing and students expect lecturers to have a route universal way of asking assessment questions and if the assessor twists the questions, the students tend to be lost and as a result they fail most of the time to employ critical thinking skills and answer the questions correctly. Thus, the current literature in the field about the inclusion of critical thinking in higher education is emphasized by many authors (Moore, 2013; Flores, Matkin, Burbach, Quinn, \& Harding, 2012; Jones, 2015; Bowell \& Kingsbury, 2015; Mulnix, 2012). There is little consensus on what constitutes CT and to what extent the perception of the concept differs in different cultures, which might be the result of a lack of a common definition of CT (Shaheen, 2012). A growing enthusiasm for CT led the American Philosophical Association to invite a panel of experts, under the leadership of Facione, to conduct a systematic investigation intended to achieve a more refined understanding of the state of affairs regarding the nature and assessment of CT. The results were later to become cornerstones of this understanding and known as the "Delphi Report". CT is defined by the panel of experts as to be: "purposeful, self-regulatory judgment which results in interpretation, analysis, evaluation, and inference, as well as explanation of the evidential, conceptual, methodological, and contextual considerations upon which that judgment is based" (Facione, 1990: p. 2) as cited in (Shaheen, 2012).

Similarly, in the case of teachers, having knowledge of what constitutes CT and how it should be valued is a key factor in contributing successfully to students' academic performance (Cosgrove, 2011). Knowing the criteria of critical thinking enhances students to write well thought of academic texts. Henceforth, Shaheen (2012) alludes that faculties and departments that teach international students face great challenges in their efforts to develop the effective use of CT, especially in terms of the academic writing of a wide variety of culturally and linguistically diverse students.

Scriven and Paul (2007, p.1) defines critical thinking as the "intellectually disciplined process of actively and skillfully conceptualizing, applying, analysing and synthesizing, and, or/ evaluating information gathered from, or generated by observation, experience, reflection, reasoning, or communication, as a guide to belief and action". Thus the importance of critical thinking is seen as a key study skill at a university level, it helps one to create strong arguments of their own, it results in the ability to draw the right conclusions more often and it gives students a head- start at university. Despite the importance of lecturing for critical thinking to Rukwangali students, there are still some major factors that cause students from not using critical thinking skills in their Rukwangali writings. 
Critical thinking is very important, because it results in the ability to draw the right conclusions more often (Zulfiqar, 2016) and tertiary level teaching awaits students to engage in critiques and make positive judgments and look at situations with divergent spectrums (i.e. thinking outside the box). Moreover, fellow Rukwangali lecturers have complained excessively about students' inability to use critical thinking skills. Henceforth, the researcher found it a ticking concern which required immediate intervention for the betterment of the students' Rukwangali academic work. This had prompted the researcher to conduct and in-depth study on students' inability of critical thinking in academic writing: perspectives of Rukwangali language lecturers' at Rundu Campus) in the Kavango East Region.

\subsection{Conceptual Framework}

The conceptual thrusts reviewed in this article are based on a social constructivism approach and the critical thinking model. The conceptual framework for this study was constructed by synthesizing social constructivism theory and the critical thinking model to identify potential conceptual links.

Kalpana (2014) ascertain that a social constructivist approach (SCA) influenced by Vygotsky's work emphasises "the social contexts of learning and that knowledge is mutually built and constructed" (p. 28). By interacting with others students get the opportunity to share their views and thus generate a shared understanding related to the concept. From Piaget to Vygotsky, "the conceptual shift is from individual to collaboration or assisted performance, social interaction and sociocultural activity. In Vygotsky's theory content of the knowledge is influenced by the culture which includes language, beliefs important to that culture and skills considered important in that culture (like computer skills, communication skills, collaboration skills).

Above all, social constructivism was founded by Lev Vygotsky (1896-1934) who was a Russian psychologist. He is considered as the father of social constructivist theory. He followed the work of John Piaget - who is attributed as the roots of constructivism. While Piaget focused on stages of child development and individual construction of knowledge, Vygotsky identified the greater socio-cultural context (Jones and Araje, 2002). In addition, Vygotsky postulates that what a child can today with assistance, she will be able to do by herself tomorrow (Jones, et al., 2002). To extend a point this entails that the pedagogy underpinning social constructivism as a theory advocates that children ought to be scarfolded as they take in new content until at a certain extend before they are left to do things on their own. That is to say, if they have reached a peak of understanding and they are deemed fit to work on their own as the lecturer facilitates the learning process. This is done by giving a task to the students to execute it on their own or in a group since the knowledge being used was gained through social interaction within the social context. This theory goes hand in hand with the phenomenon under study using key terms in the research title "critical thinking and academic writing" the reason being that critical thinking is a cognitive skill that requires a framework to be mastered and monitored from time to time (Bhavana, 2015). Accepting this, both critical thinking and academic writing are skills that are acquired through learning. And since social constructivism emphasises the importance of culture and context in understanding what occurs in society and constructing knowledge based on this understanding (Derry, 1999; McMahon, 1997) we can finally reach a consensus and postulate that critical thinking in academic writing of students can only prevail when social interaction plays a fundamental role in the process of cognitive development (Jones, et al., 2002). Concurrently, Vygotsky felt social learning precedes development. He states: "Every function in the child's cultural development appears twice: first, on 
the social level, and later, on the individual level. Social Level is between people which is called as interpsychological and then individual level which is inside the child - called intra-psychological in interpsychological level, child knowledge through contacts and interactions with people and then later the child assimilates and internalizes this knowledge adding own personal value to it in intra-psychological level (Jones, et al., 2002).

Jones, et al. (2002) asserts that the More Knowledgeable Other (MKO) refers to anyone who has a better understanding or a higher ability level than the learner, with respect to a particular task, process, or concept. The MKO is normally thought of as being a teacher, coach, or older adult, but the MKO could also be peers, a younger person, or even computers. Typical of this, this can happen very well when students' inability of critical thinking in academic writing is at stake whereby they can start as novices and as they gain momentum in the knowledge they can transfer the skill of thinking critically and employ it in their academic pieces of writings.

Vygotsky defines the Zone of Proximal Development (ZPD) as "the distance between the actual developmental level as determined by independent problem solving and the level of potential development as determined through problem solving under adult guidance or in collaboration with more capable peers" In the ZPD, a teacher and a learner work together on a task that the learner could not perform independently because of the difficulty level. Also it reflects the idea of collective activity, where those who know more or are more skilled share that knowledge and skill to accomplish a task with those who know less. A good deal of guided participation is required when working in the ZPD and learners bring their own understandings to social interactions and construct meanings by integrating those understandings with their experiences in the context (Jones, et al., 2002). To provide an illustration, when the lecturer aims at enhancing critical thinking in his/ her students' academic writing he first uses the zone of proximal development where he provides guidance until such a time when the students are able to work on their own without any guidance of some sort. That is to say, a lecturer can lecture students on how to write a certain piece of work and continue giving them guidance as they practice on the guidelines until they are fit to be left alone to try it on their own.

The central philosophy behind the decision to focus on the areas of critical argument and writer identity in understanding English First Language (EFL) students' academic writing abilities is social constructivism; a learning theory based on the ideas of Vygotsky (1978) that human development is socially situated and knowledge is constructed through interaction with others. Creswell (2009) asserts that social constructivism serves as a useful theoretical framework as it allows for necessary qualitative analysis to reveal insights on how people interact with the world. Social constructivist theory asserts that 2 people's ideas coincide with their experiences and that writer's build on their socio-cultural awareness, a key point in identity construction.

Social constructivism emphasises "the social contexts of learning and that knowledge is mutually built and constructed" (Kalpana, 2014, p. 28). By interacting with others students get the opportunity to share their views and thus generate a shared understanding related to the concept. Whereas, the Paul-Elder critical thinking model follows the following components: the elements of thought (reasoning), the intellectual standards that should be applied to the elements of reasoning, the intellectual traits associated with a cultivated critical thinker that result from the consistent and disciplined application of the intellectual standards to the elements of thought.

Based on the above distinctions, these two theories (social constructivism and critical thinking model) form a link and they are also complementing each other as the theory of social constructivism advocates that 
students who are in a social context tend to mutually build and construct knowledge together as they interact with other students to generate understanding and as they interact, their critical thinking skill is being enhanced and they can implement it better when they are left to work alone. Moreover, the Paul-Elder's critical thinking model also emphasises that a student need to portray good reasoning skills and intellectual traits associated with a cultivated thinker. It is against this background that the researcher has decided to merge the two theories (social constructivism and critical thinking model) to form a conceptual framework because all theories talk about the role of interaction and the emergent reasoning to reach an understanding. This informed the current study to answer on how lecturers can help students who have inabilities to employ critical thinking in their academic writing by using the zone of proximal development and teaching them to be logic as possible when they are involved in Rukwangali academic writing.

Working in teams helps students to achieve higher levels of thought. Information is also held longer (Johnson and Johnson, 1986; Slavin, 1990). This is supported by Totten, Sills, Digby and Russ (1991) and Gokhale, (1995) who assert that collaborative learning enables students to become critical thinkers.

\subsection{Research Problem}

Whilst a plethora of available literature has been written on critical thinking from an international and national perspective (Frans, 2014; Heffernan, 2015; Hughes, 2014, McKinley, 2013; Nandu, 2013, Nor Shidrah, 2012; Shaheen, 2012, Synder, n.d \& Vyncke, 2013) not much is known about Rukwangali students' critical thinking in academic writing at Rundu Campus). The researcher considered this investigation to be of value, and that critical thinking and academic writing and associated factors should be understood from the Rukwangali language education lecturers' perspectives.

\subsection{Research Questions}

The following research questions were addressed in this study:

1. What were the strategies that were used by Rukwangali language education lecturers in enhancing critical thinking?

2. What were the barriers that Rukwangali lecturers encountered as they taught for critical thinking in Rukwangali modules?

3. What were the hindrances Rukwangali students faced as they used critical thinking in their Rukwangali academic writing?

\subsection{Significance of the Study}

This study is a contribution to the evolution and growth of knowledge regarding critical thinking for tertiary students in their Rukwangali academic writing in Namibia. The results of this study are significant as they would inform the policy makers, curriculum designers, teachers and Rukwangali lecturers about the 
factors contributing to students' inability to use critical thinking skills in their academic writing. Thus, they can come up with possible strategies to enhance students' critical thinking skills. Teachers will benefit as they would be aware of the different strategies to enhance their students' ability to think critically and apply the skill in their academic writings which will enrich the teaching and learning process of Rukwangali modules at Rundu campus. Henceforth, the present investigation is crucially important for curriculum developers, educators and Rukwangali teachers to help them review the current issues of higher education at a policy level, especially with regard to the development of academic writing in Rukwangali. This will help in the redesign of syllabi and in improving writing instruction in order to promote CT in university level education, in line with properly addressing students' needs and developing CT pedagogy.

\section{Methodology}

\subsection{Research Design}

This study adopted a qualitative research approach using a case study design. On careful consideration, in order to gain data that is rich and personal (Cohen et al., 2011), a qualitative methodology for this study was suitable to deduce lecturers' perspectives on students' inability of critical thinking in academic writing at Rundu campus in the Kavango East Region. This study sought answers within the socially constructed nature of reality between the researcher and what is studied. The qualitative method is well designed to explore the multitudes of experiences and differences put forth by people (Denzin \& Lincoln, 2005). This further strengthens the choice of qualitative methodology for this study, as this study sets out to review the perceptions of educators (Rukwangali language education lecturers).

\subsection{Population}

The population of this study consisted of all four (4) Rukwangali language education lecturers lecturing at UNAM's Rundu Campus.

\subsection{Sample}

The sample sizes of the research were four lecturers lecturing Rukwangali modules. The purposive sampling was employed to select the sample size because purposive sampling is a sampling method that advocates using participants that are already known to have the information that the researcher is looking for. Substantively, purposive sampling is the deliberate choice of a participant due to the qualities the participant possesses (Etikan, Musa \&Alkassim, 2015, p.2).

\subsection{Research Instruments}

A semi structured interview protocol was used to four Rukwangali language education lecturers to capture their perceptions about critical thinking of Rukwangali language education lecturers in their academic writing. In addition, an observation checklist was administered to form a link between the perceptions of Rukwangali language education lecturers' during the interview sessions and what the researcher had observed during lectures. To extend a point, a document analysis guide was utilised to analyse the Rukwangali language education students' test scripts and the assignment set by the Rukwangali language education lecturers to see the questions asked by the lecturers and how the students answered the questions. 


\subsection{Procedure}

After obtaining official access to the Rukwangali language education lecturers, arrangements were made to administer in-depth interviews, followed by lecture observations and lastly, test scripts of Rukwangali language education students and test questions and assignments were analysed with four Rukwangali language education lecturers at the University of Namibia Rundu Campus in Kavango East region.

\section{Ethical Considerations}

In order to maintain a climate of trust in the practice and outcomes of social research, an ethical assurance was established and was maintained by the Rukwangali language education lecturers and the researcher. The aim and purpose of research was explained to the participants. Bryman, (2012) has suggested four significant ethical considerations for researchers to avoid; namely, lack of informed consent; harm to participants; invasion of privacy; and deception. This research study has followed the core ethical issues of informed consent, confidentiality and anonymity, and minimizing harm to participants.

\section{Data Analysis}

Whereas, the interview data from in-depth interviews were categorized and thematic analysed, observation data were analysed using a qualitative content analysis and lastly, the test questions, test scripts and assignments were analysed using a grounded theory.

\section{Results and Discussions}

To appropriately address the research questions posed in this study the researcher presented the findings of the integrated interview data, observations and document analysis guide according to identified three thematic categories namely; strategies to teach for critical thinking, perceptions towards lecturing for critical thinking and barriers to using critical thinking in academic writing and how these barriers could be mitigated.

\subsection{Strategies to teach for critical thinking in Rukwangali language education modules}

It emerged from the analysis of data that an effective way of lecturing for critical thinking is using strategies such as; peer evaluation, assessment and teacher questioning.

- Peer Evaluation Approach

Nor Shidrah (2012) suggests that peer evaluation encourages active learning among students. Both the writer and the evaluator have roles to play and both are learning through interaction. Anamer (1998) as cited in Nor Shidrah (2012) explains that working with peers provides opportunities for a student to (a) question the present quality of his/her draft (b) seek out elaboration of something that was recently learned, (c) receive constructive correction for misuse of a structural aspect of writing and (d) listen to redirection advice regarding a work in progress without the stigmatism of failure that frequently accompanies such assistance directly from a teacher ( $\mathrm{p} 268)$. 


\section{- Assessment}

Assessment is central to the integrity and accountability of a university (Ferns \& Zegwaard, 2014). Assessments should reflect how well the student has understood a particular concept and how the student can analyse and implicate the concept in different situations (Cotter \& Tally, 2009). It is crucial for the student to understand the cause and effect of the concepts rather than just applying concepts to situations without comprehending them. A study conducted by Lee (2012) made a significant suggestion to the assessment of students' thinking abilities by presenting an open-ended and exploratory approach rather than directive approach to scrutinise and comprehend students' developing thinking competence.

The purpose of assessment is to improve student's ability to think, Saxton, Belanger and Becker (2012) list three criteria that may be recognized as best practice in critical thinking assessment: First, the target of critical thinking assessment should be the thought process, focusing on the rational evaluation and explanation in the student's answer. Secondly, critical thinking assessment should invoke topic that are not directly instructed in the classroom. Thirdly, assessment of critical thinking should measure cognitive skills and critical thinking dispositions in their writing.

\section{- Teacher Questioning}

Questioning is an important way to stimulate students to think critically. If a teacher is aiming at developing his/her students' level of critical thinking skills, they should then refrain from lower lever question. This is because lower level question call for recognition of factual information previously presented, whereas higher level question call for manipulation of previously learned information to create a response, these questions go beyond memory and factual information and require students' great efforts to infer analyses and evaluate. The level of student thinking generally related to the level of question that the teacher poses if teachers systematically raise the level of their question, students tend to raise the level of their responses correspondingly (Orlich, Harder, Callalan, Trevisian, Brown \& Millet,2013). Lecturers should be careful as they use this important strategy. While setting assessment task they should make sure that there is a systematic vary in which they structure their task to incorporate higher level questions so that their students can get used to thinking critically as they involve themselves in academic writing. Students are flexible people; they answer according to the level of the questions posed assuming they were taught about/ explained to explicitly what instructional verbs questions require them to do.

When asked to mention the types of strategies they use to teach critical thinking in academic writing to Rukwangali students, three out of four noted that they use strategies such as drafting, proof-reading and peer evaluation. While one out of four said they don't use any writing strategies because their module covers listening and speaking as a skill but not writing as a skill.

In a nutshell, we can clearly conclude that lecturers do not know what strategies they can use to enhance the critical thinking of students in their academic writing. Drafting and proofreading which was termed to be strategies the lecturers used in enhancement of critical thinking in student's academic writing are not strategies but rather they constitute the writing process. This is to say that one out of the three strategies which were mentioned peer evaluation was singled out to be one of the strategies the lecturers can possibly use in enhancement of critical thinking in student's Rukwangali academic writing. This is supported by the available literature where Nor Shidrah (2012) suggests that peer evaluation encourages active learning among students. 
Both the writer and the evaluator have roles to play and both are learning through interaction. Anamer (1998) as cited in Nor Shidrah (2012) explains that working with peers provides opportunities for a student to (a) question the present quality of his/her draft (b) seek out restaurant or elaboration of something that was recently learned,(c) receive constructive correction for misuse of a structural aspect of writing and (d) listen to redirection advice regarding a work in progress without the stigmatism of failure that frequently accompanies such assistance directly from a teacher (p 268).

\subsection{Perceptions towards lecturing for critical thinking}

When asked to explain whether critical thinking could be taught and if it can, how can one teach for critical thinking? Three out of four agreed that critical thinking can be taught to students and justified with practical examples on how critical thinking could be taught. The other participant was of a different opinion that critical thinking cannot be taught but it can be evoked and natured.

Constructively, the literature support that critical thinking should be taught to students. Van Gelder (2005) as cited in Zhao, Pandia and Singh (2016) suggests that CT be practiced deliberately and taught explicitly as an indispensable part of the curriculum. Henceforth, (Bahr, 2010); Rezaei, Derakhshan and Bagherkazemi (2011) maintain that some educators believe that critical thinking cannot be taught explicitly and some feel that they do not have the capacity or confidence to teach for critical thinking.

\subsection{Barriers to using critical thinking in Rukwangali language education academic writing}

When asked to state what could be the hindrances that their students face when using critical thinking in their Rukwangali academic writing, the lecturers indicated that they have learnt that their students lack analytical skills of poems, translating content from English to Rukwangali, lack of resources in native languages, lack of research on their own, memorization, language barrier, lack of conversational sessions, insufficient time, the number of students, too much explanations from the lecturer and the subject content is narrow. It seems to occur that every lecturer experiences different hindrances from their students in terms of using critical thinking in their Rukwangali academic writing.

Interviewee number three is of the opinion that the skill of critical thinking can also be enhanced and touted when students are repeatedly involved in conversations to boost the way they think and get used of reasoning before they transfer the knowledge to writing. This is supported by the literature which is sustaining that in Social constructivism the emphasis is on the social contexts of learning and knowledge which is holistically built and constructed. It is further noted that when students interact with others they tend to share their opinions while concurrently generating a concrete comprehension related to the concept (Kalpana, 2014).

It is clear that the hindrances that emerged from the current study are consistent with the hindrances in the literature. Nine out of eleven factors are similar to the factors in the literature. The recent study revealed that hindrances that students face when using critical thinking in their Rukwangali academic writing lack analytical skills of poems, translating content from English to Rukwangali, lack of resources in native languages, lack of research on their own, memorization, language barrier, lack of conversational sessions, insufficient time, the number of students, too much explanation from the lecturer and the subject content is narrow. Whilst in the previous literature, hindrances that students face when using critical thinking in their Rukwangali academic writing are: subject knowledge, authorial voice, the essay genre, parental education, 
lack of enough efforts from colleges and universities, teacher competence, nature of students, type of learning environment, organisational ethos and resources, content driven curricular and assessment criteria.

Based on above, the deduced hindrances that emerged from the study and that of the available literature and that seem to be similar are the following:

The essay genre from the available literature and memorization as factors merge this is because in the essay genre as a factor it notes underscores that in higher education, students need to do more than acquire and reproduce knowledge; they need to transform and to recreate knowledge by using the rhetorical tool of argument. This 'transformed knowledge' or 'argument' should then be organised into a structured whole, linking the different components in a logical manner (Vyncke, 2012). When students fail to produce an argued essay, it is not necessarily due to cultural interference, but as Andrews (2007) argues, because they did not fully understand the framework of the essay genre which they have to operate within. Similarly, the factor that emerged from the study which is memorization concurs with this factor where the respondents had an opinion that students do not use critical thinking because they are prone to memorising content than fostering for understanding.

In addition, the literature brought forth that subject knowledge and the narrowed subject merge. This is because the study revealed that the Rukwangali modules offered have inadequate subject content and the exit learning outcomes do not really take a stance in supporting critical thinking but rather remembering chunks of information. These are supported by the available literature which states that sufficient subject knowledge has been regarded as an essential requirement for the development of critical thinking skills. It can be seen as the fertile soil on which the seed of critical thinking can take root and grow. Since it is impossible to think critically about something of which one knows nothing, critical thinking is dependent on a sufficient base of knowledge" (Vyncke, 2012). Andrews (2007) underscores that students' first need to acquire sufficient subject knowledge before they can attempt to develop their own position within their field and acquiring subject knowledge is therefore the crucial initial step in developing a critical dimension in their writing.

Furthermore, lack of efforts from colleges and universities merged with lack of resources in native languages. The current study revealed that the Rundu Campus' library do not have enough books in native languages which students can use when they want to conduct a research. As a result, they are forced to use the few books which are on the shelves and if they are all borrowed by other students it means that they will only get to use them after three months when they are returned and by that time the due date of submitting the assignment have passed. This is in support with the available literature which concurs with the study that little is being done in colleges and universities in developing CT skills. Henceforth, library facilities are not in good state and internet facilities. Most of the times, students consult their study guides for content only, then tapping knowledge from a variety of prescribed academic sources (Shaheen, 2012).

Teacher competence and lack of conversational sessions merge. This is because the study's findings revealed that when students are involved in sessions that allow them to express their views and when it's done often, it sharpens their way of reasoning and in the long run the critical thinking as a skill is being enhanced which they can later use in their academic writing when questions of thinking arises. Unfortunately, this was not done by the lecturers because they do not know that involving students in conversational sessions could enhance students' critical thinking skills. Hence, this is supported by the current literature which concurs with the study conducted by (Khan, 2017) were he argued that lack of background knowledge and attitudes relate 
to what critical thinking is and how to teach it makes it a hindering factor in teaching critical thinking to students.

The study has revealed again that the nature of students, lack of analytical skills of poems and lack of research on their own also intertwined. This was seen that if students lack skills of analysing which is needed to master the skill of critical thinking and if they do not research on their own they will not be proficient in thinking critically when they engage in academic writing. The nature of students has a great impact on how critical thinking in academic writing is natured and used. The available literature agrees to the findings where (Cassum, Profetto-McGrath, Gul, Ashraf and Kauser, 2013) found that teachers were well aware of the way teaching and learning are conceptualized at school level. This was seen as generating a context where students did not take learning seriously because the goal of many students was recording information dispensed by the teacher and memorising it. Thus, time spent in thinking, discussing or challenging was perhaps not valued.

To add on, the type of learning environment and too much explanation from lecturers also merged. This is because the study is of the opinion that the lectures do all the talking during lectures and it again seems to be that they do not follow the paradigm shift of learner/ student centered approach where the lecturer supposed to be the facilitator of the lesson while the students do the rest of the activities in the class. When the lesson is teacher- centered it implies that students will just be followers in the classroom which results in students not developing critical thinking as a skill. This is supported by the available literature whereby Cassum et al (2013) found that teachers were well aware of the vital role of sound student -teacher relationships. There needs to be an environment in the teaching room that allowed students to be engaged, without loss of control.

Organisational ethos and Resources also merged with the number of students which emerged from the current study. This was deduced from the participants' explanations where they alluded that the number of students in the classrooms makes them not to give full attention to individual students for them to ask questions and for the lecturers to probe their students for justifications. In addition, the resources in the classrooms are inadequate to execute the lecturing duties. The classrooms are few and students do not get enough space in the classroom do to group discussions and present to the rest of the class. This is supported by the available literature that Cassum et al. (2013) revealed that teachers are fully conscious about the need for a supportive educational culture where the goals to develop critical thinking were shared across the entire institution.

The content driven- curricula and insufficient time merged. This is because the modules taught by the researcher's participants have a lot of exit learning outcomes and it takes time for the lecturers to cover all the descriptors for each learning outcome. And the curricula seem to be rich in content than advocating for critical thinking. In this case critical thinking is totally forgotten when covering the subject content. This is supported by the available literature where Halpern (2014) has argued in the US context that the content-driven nature of many Higher Education courses hinders the development of critical thinking skills. This often arises with overloaded curricula (Chaffee, 1992; Reed and Kromrey, 2001) as cited in (Khan, 2017). Illustrating this, Paul, Elder and Bartell (1997) as cited in Khan (2017) found that, while the majority of faculty (89\%) believed that critical thinking should be a primary goal in Higher Education, more than $75 \%$ could not conceive how to cover their course content while fostering critical thinking.

Despite the factors that emerged from the current study and that merged with the factors that hinders students from using critical thinking in their academic writing in the available literature, it is found that there 
is a need to add language barrier and inability of translating content from English to Rukwangali as factors which may inhibit students from using critical thinking in their Rukwangali academic writing.

\section{Conclusions}

This qualitative study sought to describe the perceptions of Rukwangali language lecturers towards their students' inability of critical thinking in their Rukwangali academic writing at Rundu campus in the Kavango East Region of Namibia. The study concludes that there are numerous constraints that interfere with lecturers' effective teaching of critical thinking in Rukwangali language education modules. These constraints include lack of understanding on the requirements needed in teaching critical thinking skills to students, lack of training, lack of information, personal beliefs and preconceptions and time constraints.

It was concluded in the study that Rukwangali students face a number of hindrances when they attempt to use critical thinking in their academic writing. The following are the hindrances: lack of analytical skills of poems, translating content from English to Rukwangali, lack of resources in native languages, lack of research on their own, memorization, language barrier, lack of conversational sessions, insufficient time, the number of students, too much explanation from lecturers and narrow- subject content. It was also established that Rukwangali language lecturers should practice the following strategies to enhance critical thinking in Rukwangali language academic writing of students: writing, assessment, explicit/ infusion approach, teacher questioning, assessment rubrics/ scoring rubrics and peer- evaluation approach due to their relevance to academic writing.

The results of the present study provide evidence that information learned from the perceptions of Rukwangali language education lecturers towards students' inability of critical thinking in academic writing plays an important role in changing the way the lecturers perceive the notion of critical thinking in academic writing. These positive changes result in lecturers wanting to lecture for critical thinking and design questions in such a way that critical thinking is touted at Rundu campus in the Kavango East region. Generally, participants of this study demonstrated a strong belief in the effectiveness and success of articulating critical thinking in academic writing. Thus one can conclude that critical thinking in academic writing have value and it can help Rukwangali lecturers, students, the university's curriculum designers and other native language lecturers to achieve the realization of strengthening the aspect of critical thinking in academic writing in Namibia and beyond.

\section{References}

Andrews, R. (2007). Argumentation, critical thinking and the postgraduate dissertation. Educational Review, 59(1) pp.1-18.

Bahr, N. (2010). Thinking Critically about Critical Thinking in Higher Education. International Journal for the Scholarship of Teaching and Learning, 4(2).

Bhavana, M. (2015). The Teaching of Critical Thinking: Reviewing the Perceptions of Educators in Tertiary institutions in New Zealand (Master's Thesis, Unitec Institute of Technology).

Bowell, T., \& Kingsbury, J. (2015). Virtue and inquiry: Bridging the transfer gap. In M. Davies \& R. Barnett (Eds.), The Palgrave handbook of critical thinking in higher education (pp. 233-245). New York, NY: Palgrave Macmillan.

Bryman, A. (2012). Social research methods (4th ed). Oxford, New York: Oxford University Press. 
Cassum, S. H., Profetto-McGrath, J., Gul, R. B., Ashraf, D., \& Kauser, S. (2013). Multidimensionality of critical thinking: A holistic perspective from multidisciplinary educators in Karachi, Pakistan. Journal of Nursing Education and Practice, 3(7), pp.9-23.

Cohen, L., Manion, L., \& Morrison, K. (2011). Research methods in education (7th ed). New York, NY: Routledge.

Cosgrove, R. (2011) Critical thinking in the Oxford tutorial: a call for an explicit and systematic approach, Higher Education Research \& Development, 30 (3), pp. 343-356.

Cotter, E. M., \& Tally, C. S. (2009). Do Critical Thinking Exercises Improve Critical Thinking Skills? Educational Research Quarterly, $33(2), 3-14$.

Denzin, N. K., \& Lincoln, Y. S. (Eds.). (2005). The Sage handbook of qualitative research (3rd ed). Thousand Oaks, CA: Sage Publications.

Facione, P. A. (2011). Think critically (Student ed). Upper Saddle River, NJ: Prentice Hall.

Ferns, S., \& Zegwaard, K. E. (2014). Critical assessment issues in work-integrated learning. Asia-Pacific Journal of Cooperative Education, 15(3), 179-188.

Flores, K. L., Matkin, G. S., Burbach, M. E., Quinn, C. E., \& Harding, H. (2012). Deficient Critical Thinking Skills among College Graduates: Implications for leadership. Educational Philosophy and Theory, 44(2), 212-230.

Frans, T.H.N. (2014). Students' English writing skills at the polytechnic of Namibia. Nawa: Journal ofLanguage \& Communication. Retrieved June,03, From

http://ir.nust.na/bitstream/handle/10628/555/Frans.\%20Students\%20writing\%20skills\%20at\%20the\%20PoN.pdf?sequence=1\&isAll owed $=\mathrm{y}$

Gokhale, A. A. (1995). Collaborative learning enhances critical thinking. Journal of Technology Education, 7(1). Retrieved 29 April, 2019, from http://scholar.lib.vt.edu/ejournals/JTE/jtev7n1/gokhale.jte-v7n1.html

Halpern, D.F. (2014). Critical thinking across the curriculum: A brief edition of thought and knowledge. Routledge, New York.

Hughes, J. (2014). Critical Thinking in the Language Classroom. Retrieved June, 03 , 2017 from https://www.ettoi.pl/PDF_resources/Critical_ThinkingENG. Pdf

Johnson, R. T., \& Johnson, D. W. (1986). Action research: Cooperative learning in the science classroom. Science and Children, 24, 3132.

Jones, A. (2015). A Disciplined Approach To Critical Thinking. In R. Barnett \& D. Martin (Eds.), The Palgrave handbook of critical thinking in higher education.

Jones, A. (2005). Culture and context: Critical thinking and student learning in introductory macroeconomics. Studies in Higher Education, 30(3), 339-354.

Kalpana, T. (2014). A Constructivist Perspective on Teaching and Learning: A Conceptual Framework. International Research Journal of Social Sciences 3(1), 27-29.

Khan, S, I. (2017). An investigation of the concept of critical thinking in the context of a functional English course in a B.Ed. Degree in Pakistan. (Doctoral thesis, University of Glasgow).

Lee, S. (2012). Thinking conversation: An open-ended and exploratory approach to assessing student's thinking competence. New Zealand Journal of Educational Studies, 47(1), 5-17.

Moon, J. A. (2008). Critical thinking: An exploration of theory and practice. New York, NY: Routledge.

Moore, T. (2013). Critical thinking: Seven definitions in search of a concept. Studies in Higher Education, 38(4), 506-522.

Mulnix, J. W. (2012). Thinking critically about critical thinking. Educational Philosophy and Theory, 44(5), 464- 479.

Nandu, P.K. (2013). Namibian learners' and teachers' perceptions regarding English Second language writing activities: the case of 
Selected schools in Windhoek (Master's thesis, University of Namibia, Windhoek). Retrieved June, 03, 2017 From https://repository.unam.edu.na/bitstream/handle/11070/ 1992/nandu_20 13.pdf? sequence=1

Nor Shidrah, B, M, D. (2012). Developing Critical Thinking Skills in Tertiary Academic Writing through the use of an Instructional Rubric for Peer Evaluation (Doctoral thesis, University of Canterbury).

Rezaei, S., Derakhshan, A., \& Bagherkazemi, M. (2011). Critical Thinking in Language Education. Journal of Language Teaching and Research, 2(4), pp. 769-777.

Saxton, E., Belanger, S., \& Becker, W. (2012). The Critical thinking analytic rubric (CTAR): Investigating intra-rater and inter-rater reliability of a scoring mechanism for critical thinking performance assessments. Assessing Writing, 17(4), 251-270. http://doi.org/10.1016/j.asw.2012.07.002

Scriven, M., \& Paul, R. (2007). Defining critical thinking. The Critical Thinking Community: Foundation for Critical Thinking.Retrieved June 10, 2017, from http://www.criticalthinking.org/aboutCT/defie_critical_thinking.m

Shaheen, N. (2012). International Students at UK Universities: Critical Thinking -Related Challenges to Academic Writing (Doctoral thesis, University of Huddersfield). Retrieved May 2, 2018, From http://eprints.hud.ac.uk/16429/

Totten, S., Sills, T., Digby, A., \& Russ, P. (1991). Cooperative learning: A guide to research. New York: Garland.

Vygotsky, L. (1978). Mind in society: The development of higher psychological processes. Cambridge: Harvard University Press.

Zulfiqar, A. (2016). The importance of teaching critical thinking to students. Talentlens. Retrieved May 28, 2017, from http://www.talentlens.com.au/blog/teaching-critical-thinking-to-students 